\title{
Working Conditions and Health Among Italian Ageing Workers
}

\author{
Angelo d'Errico ${ }^{1} \cdot$ Chiara Ardito $^{1,2}$ (D) Roberto Leombruni ${ }^{2} \cdot$ Fulvio Ricceri $^{1,3}$. \\ Giuseppe Costa ${ }^{1,3} \cdot$ Carlotta Sacerdote ${ }^{4,5} \cdot$ Anna Odone $^{6}$. the "Italian Working Group \\ on Retirement and Health"
}

Accepted: 11 December 2021 / Published online: 12 January 2022

(c) The Author(s) 2021

\begin{abstract}
In many European countries requirements for retirement have been tightened, causing an increase in work participation of older workers, in spite their potentially poorer health may limit their work ability. This study aimed at assessing the diffusion of health problems and exposure to unfavorable working conditions among ageing workers in two Italian surveys, as well as comparing them with those observed in the same surveys conducted before the 2011 Italian pension reform tightening the normal retirement age. The 2013 National Health Survey (NHS) and Labour Force Survey (LFS) were employed to assess the prevalence of poor perceived health, health conditions and functional limitations, and of exposure to physical, psychosocial and organization factors at work, among 60-64 years workers. Poisson regression models were used to estimate Prevalence Ratios of health outcomes and unfavorable working conditions in the two surveys, compared to data from the 2005 (NHS) and 2007 (LFS) corresponding surveys, respectively. Among both men and women, approximately one quarter had at least one physical disorder or functional limitations and 15\% poor mental health. Exposure to different ergonomic factors (15-30\%) and working during unsocial hours (19\%) were particularly diffused. A significant increase in the prevalence of functional limitations and of working at night or during unsocial hours was found in 2013, compared to corresponding data from 2005 and 2007, respectively. Our results indicate that exposure to ergonomic and organizational hazards should be reduced among ageing workers, to avoid decreased work ability, health damage or early exit from the labour market.
\end{abstract}

Keywords Retirement $\cdot$ Health $\cdot$ Ageing $\cdot$ Working conditions

Chiara Ardito

chiara.ardito@unito.it

Extended author information available on the last page of the article 


\section{Introduction}

Due to an increase in life expectancy (Eurostat, 2019), most European countries have tightened requirements for retirement, through an increase in minimum age at retirement and an increase in number of years worked required before retirement. In Italy, the last structural pension reform, issued in 2011 (law 214/2011), set to equalize requisites across gender by 2018, implying an increased statutory pension age for men from 65 to 67 years and for women from about 60 to 67 , or minimum years of contribution for early retirement equal to almost 43 for men and 42 for women. As disease burden increases above 55-60 years, there is concern that those reforms increasing pension requirements may induce large numbers of older workers affected by chronic morbidity or functional limitations to continue to be in paid employment despite their health problems (Ardito \& d'Errico, 2018). A growing number of studies, adopting quasi experimental variation in the pensionable age, suggest that pension reforms delaying retirement may have detrimental effects on the health of workers who were exposed to poor working conditions before retirement (Ardito et al., 2020; Belloni et al., 2016; Blake \& Garrouste, 2019; Carrino et al., 2020; Eibich, 2015). A study assessing the impact of the 1993 French reform increasing the years of contributions required to claim full pension benefits finds a negative effect of the reform on perceived and physical health, which is borne by less educated individuals (Blake \& Garrouste, 2019). Similarly, Carrino et al. (2020), exploiting the 2010 UK pension reform tightening eligibility conditions for women, show that rising the State Pension age reduces physical and mental health among women from routine-manual occupations only. Coherently, a previous work from our research group found a higher risk of hospitalizations for cardiovascular diseases (CVDs) associated with postponed retirement, which was limited to blue collar workers, workers with lower pay and worst health at baseline (Ardito et al., 2020). This literature suggests that these detrimental effects are driven by prolonged exposure to high-strain and low-quality jobs which might be particularly harmful in a population of aged workers whose work ability and health is declining.

In particular, those working in work environments characterized by potential health hazards, such as exposure to chemicals or high noise, intense physical demands, high work pace, work in shift or during unsocial hours may be at higher risk of health consequences. In fact, older workers were reported to be more susceptible to prolonged exposure to work hazards than younger workers, especially to exposure to physical and psychosocial hazards, which appear to have a stronger impact on their health (Aittomäki et al., 2005; Burr et al., 2017; da Costa \& Vieira, 2010; de Zwart et al., 1995; Theorell et al., 2015). Different studies have found among aged workers higher prevalence of chronic morbidity (Koolhaas et al., 2014; Niedhammer et al., 2008), especially chronic musculoskeletal disorders, which are particularly common among workers after the age of 50-55 (Okunribido et al., 2011; Plouvier et al., 2011; Sim et al., 2006).

Chronic health conditions, in particular those affecting the musculoskeletal apparatus, are known to influence work ability (Jedryka-Góral et al., 2006), possibly leading to an unbalance between functional capacity and the level of work demands among older workers. In fact, although work ability decreases with age, partly as a physiological process but mainly as a consequence of intervening health conditions (Costa \& Sartori, 2007), working conditions do not seem to change considerably at older ages. In particular, bluecollar workers, who are generally employed in jobs exposed to higher levels of physical and psychosocial hazards, are those at higher risk of not being able to comply with adverse working conditions. Data from the fifth European survey on working conditions 
(EWCS), conducted by Eurofound in 2010, show quite high proportions of ageing workers exposed for more than half of working time to adverse ergonomic factors at work, which decreased only slightly after 60 years. The same small decrease was found for exposure to several workplace psychosocial factors such as high work pace, tight deadlines, low decision authority, low skill discretion, low social support from coworkers and supervisors (d'Errico, 2017), which are the psychosocial dimensions considered more detrimental for health, especially for cardiovascular (Pejtersen et al., 2015; Theorell et al., 2016) and mental health (Bonde, 2008; Theorell et al., 2015). Data from the 2015 Eurofound survey seem to indicate a slightly greater decrease in the exposure to ergonomic and psychosocial factors among older workers, although still with quite high proportions of subjects exposed to high quantitative demands and low social support (Eurofound, 2017a).

In Italy, there is a scarcity of studies documenting the prevalence of health conditions and work ability among older workers, as well as describing exposure to adverse physical and psychosocial working conditions in this age group. Some studies have investigated work ability and working conditions among Italian ageing workers (Camerino et al., 2006; Capanni et al., 2005; Converso et al., 2015; Costa \& Sartori, 2007; Marinacci et al., 2005), but these studies were conducted mainly on specific economic sectors and before the last major 2011 pension reform which raised the minimum age for retirement to 67 years for both genders. In fact, a limitation of previous studies was that a smaller amount of workers, especially manual workers, was still working after 60 years, with the possibility of a relevant health-related selection for those remaining in paid employment.

The present study intends to contribute to the current knowledge on health status and working conditions of older workers in Italy, using data from two large National Surveys representative of the Italian working population, both conducted in 2013. The analysis focuses on workers in the age group 60-64 years in 2013, who were the most hit by the increase in age at retirement, being the first group of workers who had to delay retirement and continue working because of the 2011 pension reform.

The study goes deep into describing the health and working conditions of this group of workers (employed 60-64 years old in 2013), also examining whether there were differences:

- in health status and working conditions with workers of same age in years before the 2011 pension reform, in order to verify if any changes occurred after the implementation of the reform;

- in health status with subjects of corresponding age who had retired recently, to investigate whether the retirement decision had been influenced by health status;

- in health status, functional limitations, and exposure to adverse physical and psychosocial factors at work, with 55-59 years workers, in order to assess eventual changes in their prevalence with aging, in a population of older workers still in employment for the first time.

The paper does not adopt a causal design, hence the results should be interpreted as descriptive evidence, though rigorous and obtained by adopting multivariate regression models. Furthermore, it is important to remind that the 2011 pension reform was not the unique change occurred in the years under analysis, as it was implemented just in the aftermath of the 2008 economic recession. Since the crisis has led to remarkable levels of job loss and firms' closure, it has plausibly affected the Italian workforce composition. Whereas at the beginning of the crisis Italy counted 23.1 million employed workers, the same number was roughly reached only at the end of 2019 after having fallen to a minimum 
in 2013 since the crisis started. In Italy, as in the rest of Europe (Arpaia \& Curci, 2010) and the US (Elsby et al., 2010), men and young workers were the hardest hit by the labor market downturn (D'Amuri, 2011). The construction and the manufacturing sectors, which employ mainly men and plausibly in the riskiest working activities, were the most severely hit by the crisis, covering the bulk of jobs destroyed in Italy (Reyneri, 2018). Since firms' mortality was higher among the most obsolete and less productive firms, which are those employing less qualified and less skilled workers, a compositional effect might be biasing the results, especially for what concerns men. As unskilled and less qualified workers are less likely to be employed in the aftermath of the crisis, the comparison of health and working conditions in 2013 versus 2005/2007 might be probably affected by a downward bias, thus, providing a lower bound of the potential effects of the 2011 pension reform.

\section{Materials and Methods}

\subsection{Study Population}

Data from two editions of the National Health Survey (NHS), conducted in 2005 and 2013 by the Italian National Institute of Statistics (hereafter: ISTAT) on a representative sample of the Italian population, were used to assess the proportion of 60-64 years old subjects affected by health conditions or functional limitations. In Italy, this survey is carried out periodically, generally every five years (Odone et al., 2018). The survey collects detailed information on individual and household socioeconomic characteristics and on health conditions, including perceived health, long-term chronic diseases and functional limitations, as well as on lifestyles and use of health services. The survey is based on a two-stage sampling, with municipalities as primary sampling units and households as secondary sampling units. For each household, information is gathered for all the members belonging to the family unit, partly through face-to-face interviews and partly through a self-administered questionnaire, the latter mainly used to collect information on health conditions and lifestyles. For the 2005 survey, ISTAT collected information on 128,040 subjects, distributed over 1476 Italian municipalities (ISTAT, 2008), with a participation rate of $85.7 \%$, while the NHS 2013 included 119,073 subjects from 1456 municipalities with a participation rate of $82.5 \%$ (Fabiani et al., 2016).

Two editions of the Labour Force Survey (LFS), conducted by ISTAT in 2007 and in 2013, were used to examine the proportion of 60-64 years workers exposed to adverse working conditions. This survey is also based on a two-stage sampling design (municipalities and families) and includes representative samples of the Italian population. The LFS represents the Italian component of the European Labour Force Survey, conducted in all EU countries on a continuous basis, to obtain information on employment, job search and attitudes toward the labour market of subjects in working age (Gagliardi et al., 2009). The 2007 and 2013 editions included an ad hoc module on working conditions and occurrence of work injuries (Venema et al., 2009). Subjects were interviewed by trained interviewers by means of a standardized questionnaire on socio-demographics (age, gender, marital status, household typology, educational level, occupational social class, place of residence, citizenship) and employment status, among others. At the time of the survey, information was also collected, for those who were employed, on sickness absence, employment characteristics, injuries in the previous 12 months and exposure to a set of physical and psychosocial hazards in the workplace. The LFS 2007 and 2013 collected data on 171,496 
and 153,317 subjects, respectively, with a participation rate of approximately $95 \%$ in both surveys.

\subsection{Health Conditions and Functional Limitations in the National Health Surveys}

The following health conditions were considered, based on their higher prevalence, among a list of 22 self-reported diseases in the NHS, as indicators of physical chronic morbidity: coronary heart disease, stroke, cancer, as well as chronic obstructive pulmonary disease (COPD), other cardiac diseases, and arthritis, but for the latter three only if these conditions had been treated with drugs in the previous year, to increase their specificity. The overall proportion of subjects reporting at least one of any of the health outcomes listed above, plus liver cirrhosis, renal failure, or parkinsonism, was also computed as an aggregated general indicator of physical impairment. We also considered as additional markers of general physical health the reporting of any physical limitations and of severe ones, of sickness absence in the last four weeks and presenteeism in the last year, and of bad or very bad health to the question "How is in general your health?". Self-reported anxiety or depression, overall and treated with drugs in the previous year, were instead used as makers of mental health; both definitions were examined, because of the several personal, social and cultural factors potentially influencing access to treatment for mental disorders. Another mental health indicator evaluated was the Mental Component Summary (MCS) of the SF-12, whose standardized score ranges from 0 to 100 , considering affected by poor mental health subjects with a score below 40 (Kiely \& Butterworth, 2015). The cut-off of 40 has been reported to be the one maximizing accuracy against clinical diagnoses of anxiety and depression (Kiely \& Butterworth, 2015).

\subsection{Working Conditions in the Labour Force Surveys}

Employment characteristics included type of employment (employees with permanent or temporary contract), work schedule (full-time, part-time), night shift work, working during evening, working during week-ends, number of work hours per week, perceived exposure to high risk of work injuries, bullying or discrimination, threat or violence. Furthermore, daily exposure to six types of occupational hazards was also assessed: (1) dusts, gases, vapours, fumes or chemical substances; (2) excessive noise or vibration; (3) working in awkward postures; (4) moving or carrying heavy loads; (5) performing repetitive movements with the upper limbs; (6) excessive workload.

\subsection{Data Analysis}

Data were described as means (work hours per week) and proportions (all other variables), which were compared through t-test and chi square statistics, respectively, across levels of self-reported occupational physical activity (high vs. low or absent) in the NHS 2013, to assess the burden of health conditions among workers exposed or not to high physical workload, and between manual and non-manual workers in the LFS 2013. All prevalences were estimated as weighted proportions, to take into account the sampling design of the surveys. 
Gender-specific Poisson regression models with the Huber-White sandwich estimator of variance, also known as Poisson robust regression models, were employed to estimate prevalence ratios of health conditions:

- between subjects employed in the NHS 2013 compared to those employed NHS 2005;

- between subjects 60-64 years who were still employed, compared to those who had retired within two years before the survey;

- between age groups (60-64 vs. 55-59 years) among subjects employed in the NHS 2013.

The same types of regression models were used to estimate prevalence ratios of exposure to work hazards:

- between workers 60-64 years participating in the LFS 2013 compared to those in the LFS 2007;

- between workers 60-64 years old and those 55-59 years participating in the LFS 2013.

The Huber-White sandwich estimator of variance was used in all models, in order to avoid overestimation of the variance, which is known to affect confidence intervals of relative risks in Poisson models when applied to binomial data (Barros \& Hirakata, 2003). Poisson robust regression models have been demonstrated to be an appropriate alternative to logistic regression in cross-sectional studies when examining frequent outcomes (Barros \& Hirakata, 2003). Poisson models were set up with each health outcome or each unfavourable work characteristic as the dependent variable, and with year of the survey (2013/2005-2007), age class (60-64/55-59 years) or employment status (employed/retired) as the independent variables in the three corresponding regression models. All regression analyses were adjusted for educational level (university degree, high school diploma, low secondary, primary school), geographical area of residence (North, Center, South), economic sector (6 sectors), type of employment (employee, self-employed), and household type (single, couple with children, couple without children, single parent). NHS analyses were additionally adjusted for level of household of economic resources (low, high), and LFS analyses for type of work (manual, non-manual).

In addition, differences in the number of work hours per week between LFS 2013 and 2007, as well as between workers 60-64 and 55-59 years in LFS 2013, were estimated through multiple OLS regression, adjusting for the same set of covariates.

For retired subjects in the NHS 2013, information on economic sector and type of employment was that of the last job held before retirement.

Because questions regarding exposure to some work hazards were absent in the LFS 2007, or changed between LFS 2007 and 2013 (dusts, gases, vapours, fumes or chemical substances; excessive noise or vibration; working in awkward postures; moving or carrying heavy loads; risk of work injuries; excessive workload), making answers to these questions not comparable, the comparison between the two surveys was limited to the other work characteristics considered (bullying or discrimination; threat or violence, part-time work, temporary work, night shift work, work during evening, work during week-ends, work hours per week).

To detect potential changes in health-related selection into retirement after the 2011 pension reform, the prevalence ratios of health outcomes of employed versus subjects retired within two years were estimated also for the NHS 2005 and compared with those computed for the NHS 2013, testing the interaction between year of the survey and employment/ 
retirement condition in the Poisson regression models. Similarly, prevalence ratios of health outcomes and of unfavorable working conditions among 60-64 versus 55-59 year workers were compared across NHS and LFS surveys conducted before and after the 2011 pension reform, testing the interaction between year of the survey and age class. While the interaction's $p$-values are reported and commented in the text, the corresponding models are not shown but available from the authors.

\section{Results}

Main sociodemographic and work-related features of the employed population 55-64 years participating in NHS 2005 and 2013, and in LFS 2007 and 2013, are reported in Table 1. In both surveys, a strong increase in the proportion of women and employees was found among workers 60-64 years old in 2013, compared to earlier surveys. Between LFS 2007 and 2013 the proportion of workers employed in small firms ( $\leq 10$ workers employed) remained relatively stable among both subjects 55-59 and 60-64 years (Table 1), whereas an increase of 3-4 percentage points occurred in the proportion of those employed in firms employing 10-49 workers, with a corresponding decrease in larger firms (50+ workers).

\subsection{Work Participation}

In the LFS 2007 work participation was $58.3 \%$ and $33.5 \%$ among men and women 55-59 years, and $27.6 \%$ and $9.8 \%$ among men and women 60-64 years, respectively. Corresponding figures for the LFS 2013 were $69.8 \%(+19.7 \%)$ and $46.4 \%(+38.5 \%)$ among men and women $55-59$ years, and $31.7 \%(+14.9 \%)$ and $16.9 \%(+72.5 \%)$ among men and women 60-64 years, respectively.

The number of older workers (60-64 years) increased for both men and women, from 1434 men and 558 women in the LFS 2007 (3.9\% and 2.2\% of the employed population, respectively), to 1582 men and 935 women in the LFS 2013 (5.4\% and 4.2\% of the employed population, respectively) (data not shown).

\subsection{Health}

\subsubsection{Men}

Among male workers 60-64 years, 4.2\% declared bad or very bad health, 10\% reported arthritis in therapy, $7 \%$ coronary heart disease, $4 \%$ other cardiac diseases, $2.4 \%$ COPD, $2.3 \%$ cancer, and $1.2 \%$ stroke (Table 2). Overall, $22 \%$ reported having at least one of the physical disorders considered, with almost half of them affected by arthritis treated with drugs in the previous year. About one quarter of workers referred functional limitations, although only $3.2 \%$ stated that such limitations were severe. Approximately $3 \%$ of men reported anxiety or depression, half of which were under treatment with drugs, while $13.7 \%$ was found to have a low mental health, based on the Mental Component Summary of the SF-12 questionnaire. Presenteeism was frequent, as $25 \%$ reported to have often gone to work while sick in the previous year, while $7 \%$ stated to have had a sickness absence spell in the previous month. Notably, most figures, with the exception of few severe health conditions such as coronary heart diseases (CHD) and cancer, were similar or higher in workers employed in jobs characterized by intense physical activity. Differences were 
Table 1 Prevalence of sociodemographic characteristics of employed subjects aged 55-64 years in the National Health Surveys (NHS) 2005 and 2013, and in the Labour Force Surveys (LFS) 2007 and 2013

\begin{tabular}{|c|c|c|c|c|c|c|c|c|}
\hline & \multicolumn{2}{|c|}{ NHS 2005} & \multicolumn{2}{|c|}{ NHS 2013} & \multicolumn{2}{|c|}{ LFS 2007} & \multicolumn{2}{|c|}{ LFS 2013} \\
\hline & $55-59$ & $60-64$ & $55-59$ & $60-64$ & $55-59$ & $60-64$ & $55-59$ & $60-64$ \\
\hline & $\%$ & $\%$ & $\%$ & $\%$ & $\%$ & $\%$ & $\%$ & $\%$ \\
\hline \multicolumn{9}{|l|}{ Gender } \\
\hline Men & 64.1 & 75.2 & 60.9 & 65.9 & 61.7 & 71.9 & 58.6 & 63.8 \\
\hline Women & 35.9 & 24.8 & 39.1 & 34.1 & 38.3 & 28.1 & 41.4 & 36.2 \\
\hline \multicolumn{9}{|l|}{ Educational level } \\
\hline University & 17.1 & 13.6 & 17.5 & 22.8 & 17.3 & 16.5 & 17.4 & 22.2 \\
\hline High school & 24.5 & 20.6 & 36.4 & 31.9 & 29.2 & 26.2 & 36.4 & 31.6 \\
\hline Low secondary & 31.2 & 29.3 & 37.7 & 30.4 & 31.5 & 26.0 & 37.4 & 29.6 \\
\hline Primary & 27.2 & 36.5 & 8.4 & 14.9 & 22.0 & 31.2 & 8.7 & 16.4 \\
\hline \multicolumn{9}{|l|}{ Geographical area } \\
\hline North & 45.4 & 43.8 & 47.0 & 43.2 & 45.2 & 44.0 & 49.6 & 45.9 \\
\hline Center & 21.6 & 21.3 & 21.4 & 22.7 & 21.9 & 22.3 & 21.5 & 22.6 \\
\hline South & 33.0 & 34.9 & 31.5 & 34.1 & 32.9 & 33.7 & 28.9 & 31.5 \\
\hline \multicolumn{9}{|l|}{ Type of employment } \\
\hline Employees & 65.6 & 48.7 & 74.6 & 61.1 & 70.2 & 48.9 & 75.6 & 58.7 \\
\hline Self-employed & 34.4 & 51.3 & 25.4 & 38.9 & 29.8 & 51.1 & 24.4 & 41.3 \\
\hline \multicolumn{9}{|l|}{ Economic sector } \\
\hline Manufacturing, mining & 15.9 & 12.2 & 16.1 & 13.0 & 13.7 & 7.5 & 17.1 & 12.3 \\
\hline Agriculture, fishing & 7.1 & 10.8 & 5.4 & 5.9 & 6.8 & 6.1 & 4.3 & 5.4 \\
\hline Construction & 7.5 & 10.3 & 6.5 & 7.7 & 17.4 & 16.4 & 5.2 & 6.9 \\
\hline Trading, hotels, restaurants & 16.7 & 20.4 & 15.6 & 17.8 & 8.3 & 10.4 & 11.9 & 13.3 \\
\hline $\begin{array}{l}\text { Transportation, communica- } \\
\text { tion, finance, services for } \\
\text { companies others }\end{array}$ & 22.4 & 23.6 & 21.7 & 21.8 & 29.6 & 37.2 & 26.5 & 28.9 \\
\hline $\begin{array}{l}\text { Public administration, edu- } \\
\text { cation, health care, social } \\
\text { services }\end{array}$ & 30.4 & 22.8 & 34.6 & 33.8 & 36.5 & 29.0 & 35.0 & 33.1 \\
\hline \multicolumn{9}{|l|}{ Household type } \\
\hline Single & 12.0 & 13.5 & 16.6 & 19.7 & 12.3 & 15.2 & 15.4 & 18.1 \\
\hline Couple with children & 58.6 & 46.9 & 56.3 & 45.2 & 59.8 & 49.7 & 57.4 & 46.5 \\
\hline Couple without children & 21.4 & 32.3 & 19.1 & 28.9 & 20.0 & 29.8 & 19.4 & 29.4 \\
\hline Single parent & 7.9 & 7.3 & 8.0 & 6.2 & 7.9 & 5.3 & 7.8 & 6.0 \\
\hline \multicolumn{9}{|l|}{ Household economic resources } \\
\hline Adequate & 80.7 & 76.2 & 70.4 & 71.8 & & & & \\
\hline Scarce & 19.3 & 23.8 & 29.6 & 28.2 & & & & \\
\hline \multicolumn{9}{|l|}{ Type of work } \\
\hline Manual & & & & & 49.5 & 56.9 & 47.8 & 51.8 \\
\hline Non-manual & & & & & 50.5 & 43.1 & 52.2 & 48.2 \\
\hline \multicolumn{9}{|l|}{ Firm size } \\
\hline$\leq 10$ workers & & & & & 29.2 & 39.2 & 29.1 & 38.8 \\
\hline $10-49$ workers & & & & & 30.9 & 28.9 & 34.5 & 33.3 \\
\hline $50+$ workers & & & & & 39.9 & 31.9 & 36.4 & 27.9 \\
\hline Total & 3995 & 1477 & 4649 & 1850 & 5450 & 1992 & 5852 & 2517 \\
\hline
\end{tabular}




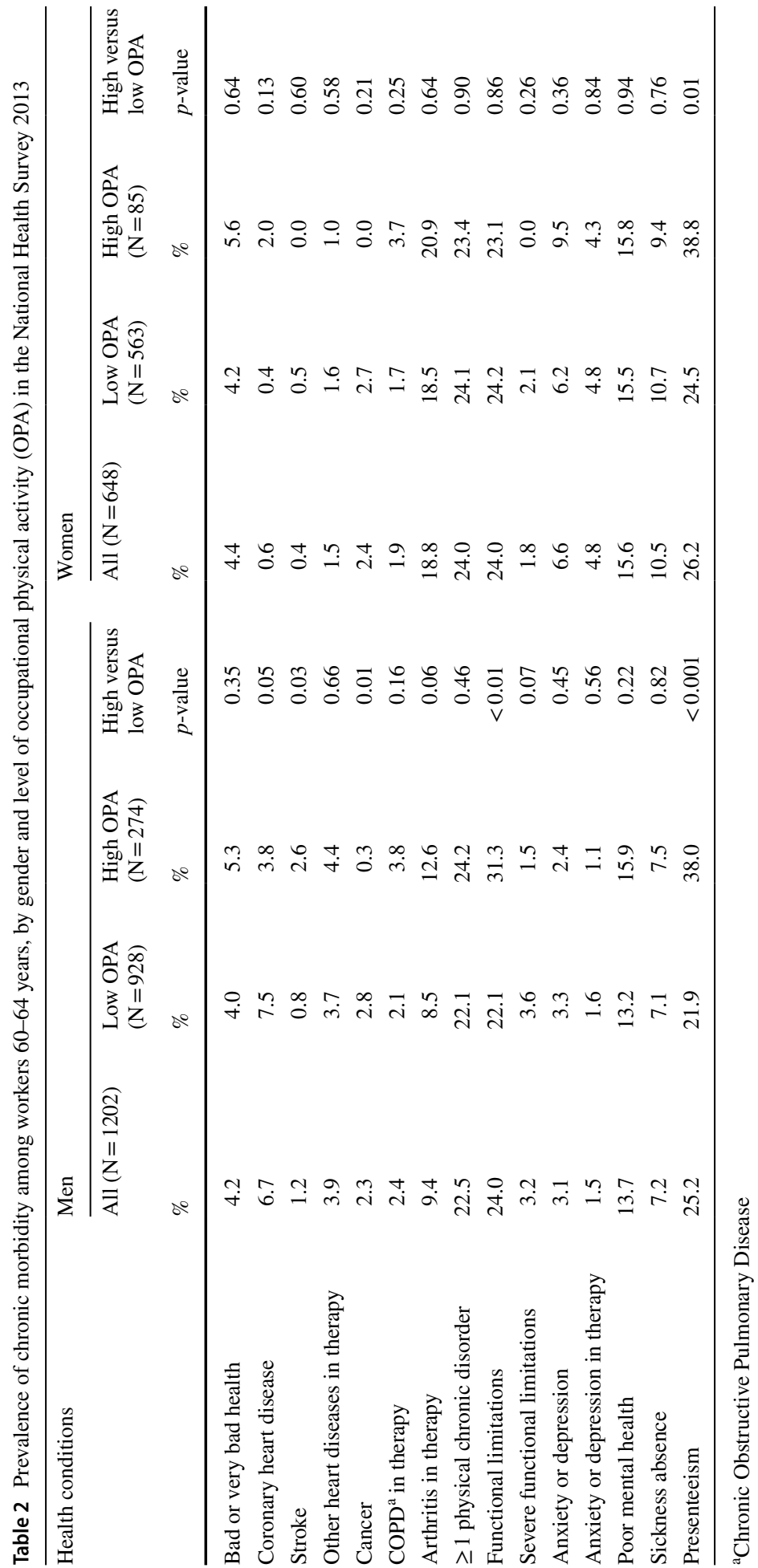


particularly large for functional limitations, showing a prevalence 10 percentage points higher among subjects in jobs with high occupational physical activity.

In comparison with the NHS 2005, in the NHS 2013 a significantly higher proportion of workers reported to have $\mathrm{CHD}(\mathrm{PR}=1.56)$ or functional limitations $(\mathrm{PR}=1.53$, while for no health condition the risk was significantly reduced (Table 3 ).

The comparison between subjects 60-64 years employed or retired in the previous two years showed significantly increased prevalence ratios among the retired for any $(\mathrm{PR}=1.23)$ and severe functional limitations $(\mathrm{PR}=1.85)$, and for other cardiac diseases $(\mathrm{PR}=1.91)$ (Table 4). Also, except for stroke, all other outcomes were more prevalent among retired subjects, although not significantly, with highest PRs observed for cancer $(\mathrm{PR}=1.76)$ and bad health $(\mathrm{PR}=1.35)$. No significant differences between PRs of health outcomes estimated for employed versus retired men were found comparing data from the NHS 2013 and 2005 (all p-values of interaction >0.05, not shown) (Tables 4, 5).

Predictably, compared to workers 55-59 years, those 60-64 years had significantly higher prevalence ratios of coronary heart disease $(P R=1.94)$, arthritis $(P R=1.29)$, any physical disorder $(\mathrm{PR}=1.40)$, and functional limitations $(\mathrm{PR}=1.20)$ (Supplementary Table 1). Furthermore, prevalence ratios of bad health $(P R=1.32)$, stroke $(P R=1.83)$, other cardiac diseases $(\mathrm{PR}=1.43)$ and cancer $(\mathrm{PR}=1.64)$ were marginally significantly increased in the older age group, compared to the younger one (Supplementary Table 1). PRs of health outcomes in older versus younger workers were not significantly

Table 3 Poisson regression Prevalence Ratios (PR) of chronic morbidity among workers 60-64 years in the National Health Survey 2013 versus 2005 , by gender

\begin{tabular}{|c|c|c|c|c|}
\hline \multirow[b]{2}{*}{$\begin{array}{l}\text { Health condition } \\
\text { (Dependent variable) }\end{array}$} & \multicolumn{2}{|c|}{$\operatorname{Men}(\mathrm{N}=2312)$} & \multicolumn{2}{|c|}{$\begin{array}{l}\text { Women } \\
(\mathrm{N}=1015)\end{array}$} \\
\hline & PR & $95 \% \mathrm{CI}$ & PR & $95 \% \mathrm{CI}$ \\
\hline Bad or very bad health & 0.97 & $0.63-1.50$ & 0.75 & $0.42-1.34$ \\
\hline Coronary heart disease & 1.56 & 1.07-2.29 & 0.51 & $0.09-2.98$ \\
\hline Stroke & 1.23 & $0.53-2.86$ & 0.38 & $0.08-1.89$ \\
\hline Other heart diseases in therapy & 1.26 & $0.80-1.98$ & 0.57 & $0.24-1.38$ \\
\hline Cancer & 1.11 & $0.55-2.22$ & 0.85 & $0.34-2.12$ \\
\hline $\mathrm{COPD}^{\mathrm{a}}$ in therapy & 0.76 & $0.47-1.25$ & 1.11 & $0.47-2.59$ \\
\hline Arthritis in therapy & 0.80 & $0.86-1.18$ & 0.92 & $0.70-1.20$ \\
\hline$\geq 1$ physical chronic disorder & 1.00 & $0.86-1.18$ & 0.96 & $0.78-1.21$ \\
\hline Functional limitations & 1.53 & $1.29-1.81$ & 1.41 & $1.08-1.83$ \\
\hline Severe functional limitations & 1.15 & $0.71-1.85$ & 0.31 & $0.13-0.73$ \\
\hline Anxiety or depression & 0.73 & $0.47-1.13$ & 0.86 & $0.52-1.41$ \\
\hline Anxiety or depression in therapy & 0.75 & $0.39-1.45$ & 1.12 & $0.57-2.18$ \\
\hline Poor mental health & 1.16 & $0.91-14.7$ & 1.06 & $0.76-1.48$ \\
\hline Sickness absence & 1.32 & $0.93-1.88$ & 1.17 & $0.76-1.82$ \\
\hline
\end{tabular}

The table displays the PR for each health condition (dep. var.), stratified by gender, estimated in NHS 2013 versus NHS 2005 using Poisson robust regression models adjusted for: geographical area, education, household economic resources, household typology, economic sector, type of employment. In bold PRs significantly different from 1 at $5 \%$ significance level

${ }^{a}$ Chronic Obstructive Pulmonary Disease 
Table 4 Poisson regression Prevalence Ratios (PR) of chronic morbidity among subjects 60-64 years retired versus employed in the National Health Survey 2013, by gender

\begin{tabular}{|c|c|c|c|c|}
\hline \multirow[b]{2}{*}{ Health conditions } & \multicolumn{2}{|c|}{$\operatorname{Men}(\mathrm{N}=1555)$} & \multicolumn{2}{|c|}{$\begin{array}{l}\text { Women } \\
(\mathrm{N}=895)\end{array}$} \\
\hline & PR & $95 \% \mathrm{CI}$ & PR & $95 \% \mathrm{CI}$ \\
\hline Bad or very bad health & 1.35 & $0.79-2.30$ & 0.91 & $0.42-1.99$ \\
\hline Coronary heart disease & 1.05 & $0.65-1.71$ & 1.81 & $0.38-8.64$ \\
\hline Stroke & 0.82 & $0.25-2.65$ & 6.83 & $1.63-28.6$ \\
\hline Other heart diseases in therapy & 1.91 & $1.14-3.21$ & 1.40 & $0.54-3.65$ \\
\hline Cancer & 1.76 & $0.87-3.57$ & 1.83 & $0.82-4.10$ \\
\hline $\mathrm{COPD}^{\mathrm{a}}$ in therapy & 1.05 & $0.49-2.25$ & 2.30 & $1.00-5.32$ \\
\hline Arthritis in therapy & 1.03 & $0.73-1.46$ & 1.27 & $0.96-1.68$ \\
\hline$\geq 1$ physical chronic disorder & 1.14 & $0.91-1.42$ & 1.32 & $1.05-1.67$ \\
\hline Functional limitations & 1.23 & 1.01-1.50 & 1.20 & $0.95-1.53$ \\
\hline Severe functional limitations & 1.85 & 1.07-3.18 & 2.13 & $0.86-5.27$ \\
\hline Anxiety or depression & 1.09 & $0.59-2.03$ & 1.14 & $0.65-2.00$ \\
\hline Anxiety or depression in therapy & 1.07 & $0.43-2.69$ & 1.01 & $0.51-2.03$ \\
\hline Poor mental health & 0.79 & $0.56-1.11$ & 0.76 & $0.51-1.13$ \\
\hline
\end{tabular}

Restricted to subjects who had retired within 2 years before the NHS 2013

The table displays the PR for each health condition (dep. var.), stratified by gender, estimated in retired versus employed using Poisson robust regression models adjusted for: geographical area, education, household economic resources, household typology, economic sector, type of employment. In bold PRs significantly different from 1 at $5 \%$ significance level

${ }^{\mathrm{a} C h r o n i c}$ Obstructive Pulmonary Disease

different between 2013 and 2005 surveys (Supplementary Tables 1 and 2, p-values of interaction $>0.05$, not shown).

\subsubsection{Women}

With respect to men 60-64 years, women of similar age showed a much higher prevalence of arthritis (19\%) and anxiety or depression (6.6\%), and a lower prevalence of cardiovascular diseases (2.5\%) and of severe functional limitations (1.8\%) (Table 2). The prevalence of low mental health based on the Mental Component Summary of the SF-12 questionnaire was instead only slightly higher than among men (15.6\% vs. $13.7 \%)$. Overall, $4.4 \%$ reported bad or very bad health and $24 \%$ at least one physical disorder among those considered, which was slightly higher than men's data. On the contrary, $10 \%$ had a sickness absence in the previous months and $26 \%$ went often to work while sick in the previous year. Only presenteeism was significantly more prevalent among those employed in jobs with high occupational physical activity. In this group, no cases of women with stroke, cancer or severe functional limitations were found, showing that health selection into these jobs likely occurred for those affected by more severe health disorders.

Employed women participating in the NHS 2013, compared to those in the NHS 2005, displayed a significant higher prevalence ratio (PR) for functional limitations 
Table 5 Poisson regression Prevalence Ratios (PR) of chronic morbidity among subjects 60-64 years retired versus employed in the National Health Survey 2005, by gender

\begin{tabular}{|c|c|c|c|c|}
\hline \multirow[b]{2}{*}{ Health conditions } & \multicolumn{2}{|c|}{$\operatorname{Men}(\mathrm{N}=1555)$} & \multicolumn{2}{|c|}{$\begin{array}{l}\text { Women } \\
(\mathrm{N}=895)\end{array}$} \\
\hline & PR & $95 \% \mathrm{CI}$ & PR & $95 \% \mathrm{CI}$ \\
\hline Bad or very bad health & 1.11 & $0.68-1.80$ & 1.15 & $0.57-2.35$ \\
\hline Coronary heart disease & 1.27 & $0.74-2.20$ & 0.78 & $0.04-15.5$ \\
\hline Stroke & 1.72 & $0.59-5.04$ & 2.37 & $0.42-13.5$ \\
\hline Other heart diseases in therapy & 1.96 & $1.17-3.28$ & 0.43 & $0.16-1.14$ \\
\hline Cancer & 1.01 & $0.41-2.49$ & 0.39 & $0.14-1.12$ \\
\hline $\mathrm{COPD}^{\mathrm{a}}$ in therapy & 1.20 & $0.69-2.08$ & 3.06 & $1.17-7.99$ \\
\hline Arthritis in therapy & 1.23 & $0.95-1.59$ & 0.93 & $0.68-1.28$ \\
\hline$\geq 1$ physical chronic disorder & 1.28 & $1.06-1.55$ & 0.97 & $0.74-1.29$ \\
\hline Functional limitations & 1.22 & $0.96-1.54$ & 0.77 & $0.55-1.08$ \\
\hline Severe functional limitations & 2.04 & $1.21-3.43$ & 0.78 & $0.33-1.84$ \\
\hline Anxiety or depression & 1.01 & $0.56-1.81$ & 1.05 & $0.56-1.97$ \\
\hline Anxiety or depression in therapy & 1.63 & $0.72-3.67$ & 1.03 & $0.40-2.64$ \\
\hline Poor mental health & 0.98 & $0.70-1.38$ & 1.33 & $0.91-1.95$ \\
\hline
\end{tabular}

Restricted to subjects who had retired within two years before the NHS 2005

The table displays the PR for each health condition (dep. var.), stratified by gender, estimated in retired versus employed using Poisson robust regression models adjusted for: geographical area, education, household economic resources, household typology, economic sector, type of employment. In bold PRs significantly different from 1 at $5 \%$ significance level

${ }^{\mathrm{a} C h r o n i c}$ Obstructive Pulmonary Disease

$(\mathrm{PR}=1.41)$ (Table 3). In contrast, the risk of severe functional limitations was significantly lower $(\mathrm{PR}=0.33$ ), although the estimate was based on few observations.

Significantly increased PRs were estimated in the NHS 2013 among retired, compared to employed women, for stroke $(P R=6.83)$, COPD $(P R=2.30)$ and any physical disorder ( $P R=1.32)$. Except for bad health, all PRs were above one, with marginally significantly increased risks for arthritis $(P R=1.27)$ and for any functional limitation $(P R=1.20)$ (Table 4). As for men, none of the PRs of health outcomes estimated for employed versus retired women was significantly different between NHS 2013 and 2005 (all $p$-values of interaction $>0.05$, not shown) (Tables 4, 5).

In contrast to men, PRs of health conditions among employed women 60-64 years, compared to those 55-59 years, were mostly below one, with no significant differences observed between the two age groups and with only the presence of any physical disorder showing a weak marginally significant association $(P R=1.14)$ (Supplementary Table 1). A significant decrease in the PRs for other cardiac diseases and severe functional limitations associated with higher age class was observed in the NHS 2013, compared to the NHS 2005 survey ( $p$-value for interaction: 0.02 and 0.05 , respectively, not shown) (Supplementary Tables 1 and 2). 


\subsection{Working conditions}

\subsubsection{Men}

From data of the LFS 2013, a quite high proportion of male workers 60-64 years reported daily exposure to ergonomic risk factors, including repetitive movements of the upper limb (33\%), awkward postures (23\%) and moving or handling heavy loads (11.5\%) (Table 6). Exposure to indoor environmental pollution, high noise or vibration, and injury risk was also quite common, with exposed proportions above $10 \%$. Twelve percent of the workers had a part-time job and $4.2 \%$ a temporary contract, while $9 \%$ did night shift work, and almost $20 \%$ used to work at evening or during week-ends, with an average of approximately 37 working hours per week. Unfavorable working conditions were in general more prevalent among manual workers, especially exposure to ergonomic risk factors, environmental indoor pollution and noise, and injury risk, all hazards showing proportions of exposure ranging from 15 to $40 \%$ in the manual group. Only exposure to high workload (10.6\%), bullying (5.1\%) and threat or physical violence $(1.6 \%)$ was more common among non-manual workers.

Compared to the LFS 2007, 60-64 years male workers participating in the LFS 2013 were more likely to be exposed to all the work characteristics investigated, although with statistically significant differences limited to night shift work $(\mathrm{PR}=1.52)$, working during evening $(\mathrm{PR}=1.23)$ or during week-ends $(\mathrm{PR}=1.29)$, and working part-time $(\mathrm{PR}=1.04)$ (Table 7). An average reduction of about one hour per week was observed in 2013, compared to $2007(p=0.10)$.

In comparison with the younger age group (55-59 years), older workers showed significantly reduced PRs of exposure to most of work hazards in the LFS 2013, including dust, fumes, gases and vapours $(\mathrm{PR}=0.84)$, excessive noise or vibration $(\mathrm{PR}=0.75)$, awkward postures $(\mathrm{PR}=0.86)$, high workload $(\mathrm{PR}=0.70)$, injury risk $(\mathrm{PR}=0.84)$, and bullying or discrimination $(P R=0.60)$, while the reduced risk for repetitive movements $(\mathrm{PR}=0.92)$ and the reduction in work hours per week $(-0.82, p$-value $=0.06)$ were only marginally significant. In the older age group, only the prevalence of part-time work $(\mathrm{PR}=1.05)$ and temporary work $(\mathrm{PR}=1.88)$ was significantly increased, compared to the younger one (Supplementary Table 3). No significant differences in PRs for any work hazard were observed for men 60-64 versus 55-59 years between LFS 2007 and 2013 (Supplementary Tables 3 and 4).

\subsubsection{Women}

Employed women 60-64 years had similar high proportions of exposure than men to most ergonomic hazards, except for moving/handing heavy loads, which was around $10 \%$ (Table 6). High workload was more common than among men $(10.7 \%)$, while night shift work (7\%) and working during unsocial hours were slightly less prevalent. Moreover, prevalence of part-time work was the double among women (26\%) and was especially common among manual workers (39\%). For all the other job features, exposure was lower, below 10\%. Differences between manual and non-manual workers appeared attenuated compared to men, with the exception of moving/handing heavy loads, and working at night or during unsocial hours, all showing much higher proportions of exposed among manual workers. 


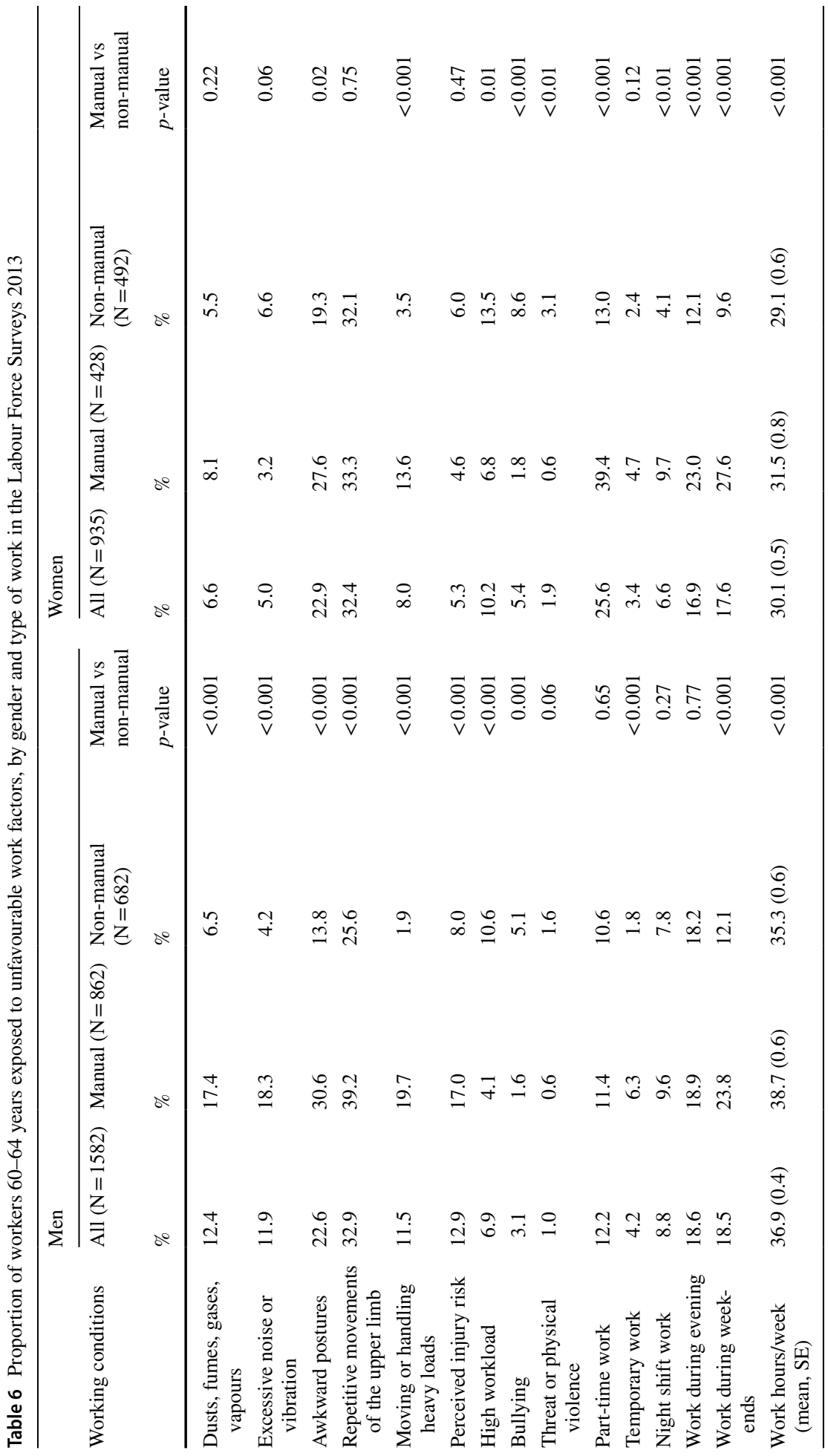


Comparing work characteristics in the LSF 2013 with those in the LFS 2007, women participating in the 2013 survey showed significantly high prevalence ratios of parttime work $(\mathrm{PR}=1.06)$, and of exposure to bullying or discrimination $(\mathrm{PR}=1.83)$, night shift work $(\mathrm{PR}=2.28)$, working at evening $(\mathrm{PR}=1.83)$ or during week-ends $(\mathrm{PR}=1.57)$ (Table 7).

Similarly to what found among men, the comparison of women 60-64 years with those 55-59 years showed in the oldest age group a modest reduction in the prevalence ratio for most of the hazards considered, although with no significant differences between the two groups, except for a reduction of more than one hour worked per week ( $p$-value $=0.03$ ) and a slightly increase in part-time work $(\mathrm{PR}=1.04)$ (Supplementary Table 3$)$. A significant increase in the PRs of working during week-ends was found for women 60-64 versus 55-59 years between LFS 2007 and 2013 (p-value for interaction: 0.05) (Supplementary Tables 3 and 4).

\section{Discussion}

\subsection{Health}

The results of the present study show that in Italy in 2013 almost one quarter of male and female workers $60-64$ years was affected by physical health conditions and functional limitations, with small differences by level of occupational physical activity (OPA), except for functional limitations among men and presenteeism in both gender, which were more prevalent among workers with high OPA, and CHD and cancer, more common among men with low OPA. Our results appear consistent with those of other studies assessing the prevalence of health conditions in populations of ageing workers. For example, a study conducted on SHARE (Survey of Health, Ageing and Retirement in Europe) data showed that 26\% European workers aged 50 years and older had at least one chronic disease (Scharn et al., 2019). Also, in two Dutch surveys, one third and one half of workers aged 45 or more, respectively, reported to be affected by a chronic disease (Koolhaas et al., 2014; Leijten et al., 2015). In France, 18\% men and 22\% women aged 50 or more who participated in the SUMER survey reported poor physical health, defined as having a score of 1 to 5 on 10-point scale (Niedhammer et al., 2008).

The most common disorder was arthritis, especially among women (19\%) and among men with high OPA (13\%). Different European surveys have observed similarly high proportions of older workers affected by musculoskeletal pain associated with functional limitations, with prevalences ranging from around 10\% to more than $20 \%$ (Fernandez-Lopez et al., 2008; Gourmelen et al., 2007; Gouveia et al., 2016; Gummesson et al., 2003; Saastamoinen et al., 2005).

Previous research has shown that workers with chronic health conditions have greater problems in performing their job, greater need of supervisors' and coworkers' support, and reduced work ability (Koolhaas et al., 2012), as measured by the Work Ability Index (WAI) (Ilmarinen et al., 1997). Furthermore, work ability appears more influenced by chronic health conditions rather than by age itself, which has been shown to explain less than $10 \%$ reduction in the WAI score during working life (Tobia et al., 2005). In a Finnish study, 26\% of workers 50-64 years reported low capacity of physical work, which is similar to the proportion of workers with physical limitations observed in our study (Miranda et al., 2010). The large proportion of subjects referring to have gone often to work while sick, especially 
Table 7 Poisson regression Prevalence Ratios (PR) of exposure to physical, psychosocial and organizational factors in the Labour Force Surveys 2013 versus 2007, by gender

\begin{tabular}{|c|c|c|c|c|}
\hline \multirow[b]{2}{*}{$\begin{array}{l}\text { Job exposure/characteristic } \\
\text { (Dependent variable) }\end{array}$} & \multicolumn{2}{|c|}{$\operatorname{Men}(\mathrm{N}=3016)$} & \multicolumn{2}{|c|}{ Women $(\mathrm{N}=1493)$} \\
\hline & PR & $95 \% \mathrm{CI}$ & PR & $95 \% \mathrm{CI}$ \\
\hline Bullying & 1.33 & $0.79-2.23$ & 1.83 & $1.01-3.31$ \\
\hline Threat or physical violence & 1.45 & $0.70-3.00$ & 1.43 & $0.67-3.02$ \\
\hline Part-time work & 1.04 & 1.01-1.06 & 1.06 & $1.02-1.10$ \\
\hline Temporary work & 1.15 & $0.85-1.56$ & 0.70 & $0.41-1.20$ \\
\hline Night shift work & 1.52 & $1.18-1.96$ & 2.28 & $1.34-3.87$ \\
\hline Work during evening & 1.23 & $1.05-1.44$ & 1.83 & $1.36-2.46$ \\
\hline \multirow[t]{2}{*}{ Work during week-ends } & 1.29 & $1.11-1.51$ & 1.57 & $1.23-2.01$ \\
\hline & Coeff & $p$-value & Coeff & $p$-value \\
\hline Work hours/week & -0.94 & 0.10 & -0.52 & 0.53 \\
\hline
\end{tabular}

The table displays the PR for each job exposure (dep. var.), stratified by gender, estimated in LFS 2013 versus LFS 2007 using Poisson robust regression models adjusted for: geographical area, education, household typology, economic sector, type of employment, occupational class. In bold PRs significantly different from 1 at $5 \%$ significance level. OLS model adjusted for the same set of covariates is used with the "Work hours/week" dependent variable

among workers with high OPA, seems to prove the difficulty of older workers with health problems in adapting to the high physical demands of their jobs.

Regarding mental health, about one tenth of 60-64 years old women reported anxiety or depression, almost half of which were under treatment with drugs, while a much lower proportion was found among men (3\%), in line with gendered patterns of mental health documented in the Italian general population (de Girolamo et al., 2006).

In contrast, a higher prevalence of depression was present among workers 50-63 years participating in the SHARE study, although with high variability among European countries, ranging from 12\% in Germany to $27 \%$ in France (Qiao et al., 2019). Another study combining data from SHARE and ELSA estimated an overall prevalence of depressive symptoms of 14\% among workers 50-64 years (Siegrist et al., 2012), similar to that observed in a Swedish study (Nyberg et al., 2019). However, lower prevalences of depression, more similar to what we found, have been observed in other studies among ageing workers (De Breij et al., 2020; Leijten et al., 2015; Mezuk et al., 2011). Anyway the variability in mental disorders prevalences in different countries was expected, as diagnosis and treatment of common mental disorders (i.e. depression and anxiety and stress-related disorders) are strictly related to educational level and have a different geographical spread (Dorner \& Mittendorfer-Rutz, 2017).

In 2013 there were only few significant differences in the proportion of health conditions, compared to 2005, indicating that no important health changes occurred until that year in the composition of the older workforce, although several PRs were estimated on small numbers of outcomes. However, among men, the increase in CHD prevalence by $56 \%$ in 2013 , with respect to 2005 , seems to indicate that a greater proportion of male workers affected by this disease were precluded early retirement in more recent years, compared to the pre-reform period. Moreover, in both genders functional limitations increased by about $40-50 \%$, suggesting that in the most recent survey the workforce participating in paid employment had on average more difficulties in performing daily activities due 
to their physical problems. The limited increase in prevalence of health conditions in the NHS 2013, compared to the NHS 2005, is possibly attributable to the relatively short time elapsed since the implementation of the 2011 pension reform; however, while only a modest increase in work participation across surveys was observed among men 60-64 years, among women it almost doubled, indicating that the reform had, after just a couple of years, a rather strong impact on women's employment at older age.

Compared to subjects still employed, men who retired in the two previous years had increased risks of other cardiac diseases, any and severe functional limitations, and cancer, although for the latter the increase was not significant. However, most disorders showed PRs close to one, indicating that health-related selection towards retirement occurred mainly for more severe health conditions. In contrast, among retired women PRs were increased for most disorders, although significantly only for few outcomes because of the small number of cases, suggesting that a stronger health selection for remaining in paid employment occurred among older women than men. A statistical comparison of PRs of health outcomes for employed versus retired subjects did not show significant differences among men or women between PRs in the NHS 2005 and 2013, indicating that the level of health selection toward retirement remained quite stable across surveys. A stronger health selection among women was also found in Germany (Kröger, 2016), while no significant gender differences were documented by a pan-European study based on SHARE (Hoffmann et al., 2019). The health selection interpretation appears justified by the relatively short time elapsed since retirement, which makes unlikely that the higher prevalence of the health conditions found among retired women, including mostly chronic disorders, could be attributable to higher exposure to health hazards after retirement. Health status is an acknowledged factor influencing exit from paid employment, as shown by several longitudinal studies demonstrating that both perceived poor health and presence of chronic disorders or disability are associated with unemployment and premature retirement (Karpansalo et al., 2004; Schuring et al., 2007, 2013; van den Berg et al., 2010).

The results of the comparison of health status between workers 55-59 and 60-64 years also supports the hypothesis of a stronger selection based on health among women than men. In fact, as expected, older men were at higher risk for all health conditions than younger men, although significantly only for a few of them, whereas older women showed reduced risks for most disorders, suggesting that those affected by health conditions were more likely to retire earlier. No significant differences between PRs by age class were found across surveys in men, whereas in women PRs decreased significantly for a couple of health outcomes (other cardiac diseases, severe functional limitations), suggesting a stronger health-related selection for these conditions in 2013, compared to 2007.

\subsection{Working conditions}

Regarding working conditions, a high prevalence of exposure was observed in the group of workers aged 60-64 years for many hazards, in particular for exposure to ergonomic factors, but also to dust, fumes, gases or vapours, excessive noise or vibration, and injury risk, in particular among male manual workers, where the proportion of exposed subjects was above $15 \%$. Higher prevalences of exposure to work hazards among ageing workers have been found in several studies, although the comparability with our results is limited by differences in the age groups examined, as well as how exposure has been measured (Lallukka et al., 2020; Leijten et al., 2015; Robroek et al., 2013). Working during unsocial 
hours, i.e. at evening or during week-ends, was also quite common, especially among manual workers, with proportion of exposed subjects around or above $20 \%$.

Exposure to adverse physical and psychosocial working conditions has been found in several studies to increase the risk of early exit from paid employment (d'Errico et al., 2020; Friis et al., 2007; Sundstrup et al., 2018), especially among subjects affected by chronic diseases (Boot et al., 2014). Therefore, in order to retain older subjects at work, physical work demands and exposure to other unfavorable work characteristics should be adapted according to health status and corresponding work ability of each worker. However, it seems likely that most companies will not have sufficient financial resources to adapt work conditions to a significant number of workers with functional limitations or serious chronic diseases. As a consequence, these employees would risk both unemployment and disability retirement, which at the individual level could decrease dramatically their income and at the society level determine an increase in expenditure of social benefits.

Of particular concern, it's that compared to LFS 2007, in LFS 2013 in both genders significantly increased PRs were estimated for night shift work and for working both during evenings and during week-ends; part-time work prevalence was also significantly higher in 2013, although such an increase was very small. As the analysis was controlled for several socioeconomic covariates, such differences are unlikely explained by changes occurred between the two surveys in the distribution of older workers by economic sector, type of employment or socioeconomic position. These results turn to be in line with an overall trend documented for the general working population for Europe during the period observed in the analysis. As reported in two recent Eurofound reports, the proportion of workers reporting working Sundays and shift work increased from 2005 to 2015 (Eurofound, 2017b), as well as the incidence of involuntary part-time during the years 2008-2013 (Eurofound, 2020). Despite being part of a general tendency observed in the labour market, the concern is that it regards the oldest and more vulnerable segment of the workforce, which seems more susceptible to the possible health effects of shift work, in particular of night shift. Older workers seem to have a reduced tolerance to shift work than younger ones, due to a higher susceptibility to the effects of circadian disruption of shift work (Andlauer et al., 1979). A systematic review on this subject concluded that, although results among studies are not fully consistent, most of the studies examined actually found that older shift workers are at higher risk than younger ones of developing several physiological changes, such as sleepiness, short sleep duration, longer time for recovery after work, and decreased performance at functional tests, possibly increasing the risk of cardiovascular diseases and other health conditions (Saksvik et al., 2011).

Unfortunately, changes in the format of the answers to questions on exposure to several of the hazards considered limited the number of items that were meaningfully comparable across the two surveys.

In 2013, workers 60-64 years of both genders were less likely to be exposed than their younger counterparts (55-59 years) to most of the work hazards considered, although in general with moderate risk reductions, which were slightly stronger and more significant among men. This finding indicates that the proportion of workers exposed to adverse working conditions did not decrease substantially after 59 years, but for most hazards was only 10-15\% lower than among workers 55-59 years, with quite small changes in PRs by age class across LFS surveys. One exception was employment with temporary contract among men, whose prevalence almost doubled in the older age group; this might be the result of a voluntary reduction of labour market attachment as a sort of coping strategy to reduce their time of exposure to physically or mentally demanding work activities, but it could also be involuntary pushed by the aggravated economic conditions driven by the economic 
recession, as older workers generally have greater difficulties in finding employment after a job loss (Wanberg et al., 2016).

\subsection{Strengths and Limitations}

Main strengths of the study are the large sample size and its representativeness, which allows on one hand to focus the analysis on a narrow age group with a relatively high statistical power, on the other hand to generalize our findings to the whole Italian working population of corresponding age. This is the first time that detailed measures of physical health, mental health, work-related physical, psychosocial, and organizational factors at work are assessed simultaneously and compared across time in a sample of Italian older workers.

Among limitations, the self-reported nature of health conditions and functional limitations, as well as of exposure to working conditions, may have caused an overestimation of the prevalences, because of differential misclassification of the exposure or of the health conditions. In particular, it seems possible that subjects affected by health conditions may have overestimated their exposure to workplace hazards, due to a greater difficulty in performing their work duties. What's more, lack of information on health in the LFS does not allow to assess whether such bias occurred. The time trend description of health and working conditions before and after the 2011 pension reform cannot be given any causal interpretation as the design of the study is descriptive. Moreover, the 2008 economic recession hitting Italy in the same period may have influenced the workforce composition, as suggested also by the reduction of workers observed in large companies and the corresponding increase in middle-size companies in the LFS 2013. Since it is likely that the 2013 sample has been affected by a stronger selection based on workers' health and skill level, our estimates are likely to be a lower bound of the possible effects of the 2011 pension reform extending working life.

Increased automation during the years of economic recession may have also concurred to select older workers out of the labour force, especially those employed in manufacturing, with the consequence of a possible underestimation of the observed prevalence of health conditions and of exposure to work hazards. However, different studies have found automation to have produced small effects on the level of employment in European countries (Dauth et al., 2018; Dottori, 2021; Klenert et al., 2020). Furthermore, in spite an improvement of working conditions due to increased automation could have been expected, it has been shown that in Italy the diffusion of automation technology during the years between the surveys remained practically the same (Carbonero et al., 2020).

\section{Conclusions}

In conclusion, the present study found, among workers aged 60-64 years in 2013, rather high prevalences of subjects reporting physical limitations or affected by health conditions potentially limiting their work ability, as well as high proportions of subjects exposed to unfavourable working conditions. The comparison with 2005 and 2007 suggests, if any, the trend is going toward a moderate deterioration in working conditions, health and functional limitations, with clearly no sign of improvement neither for health indicators nor for working conditions outcomes. 
While Italy, as well as most European countries, are tightening eligibility conditions for retirement, exposure to workplace hazards should be reduced among older workers, both because their high susceptibility to potential health effects, and to avoid that their reduced work ability would increase their early exit from the labour market through periods of unemployment, long-term sickness absence or disability retirement, in the impossibility of regular retirement. These forms of early labour market withdrawal have indeed costly consequences at both individual and societal level, potentially determining income loss and social exclusion, and increasing the burden on the welfare system to address them. As a substantial proportion of companies are expected to not have enough resources to adjust their workplaces to the reduced work ability of part of their older employees, there is a need for greater flexibility in the timing of retirement (potentially with ad hoc and constantly updated exemptions for workers exposed to jobs potentially harmful for their health) or structural public interventions to help and support companies in their transition toward more ageing friendly working environments to manage the health-related problems of workers and adapt working conditions to their age. This would allow subjects with health conditions limiting their work activities to decide whether continue to work or not during the last years of their working career, also in consideration of their working conditions, possibly without substantial income reduction in case of retirement.

Supplementary Information The online version contains supplementary material available at https://doi. org/10.1007/s11205-021-02862-w.

Acknowledgements None.

Funding The current study has been funded partly by the Italian Ministry of Health (Project No. RF-201602364270) and partly by the Fondazione Cariplo programme on Aging and Social Research (Project No. 2018-0863).

\section{Declarations}

Conflict of interest The authors declare that they have no conflict of interest.

Ethical statement No approval from an Ethics Committee was requested for this study, as it was conducted on public data, made freely available by the Italian National Institute of Statistics (ISTAT), Rome.

Open Access This article is licensed under a Creative Commons Attribution 4.0 International License, which permits use, sharing, adaptation, distribution and reproduction in any medium or format, as long as you give appropriate credit to the original author(s) and the source, provide a link to the Creative Commons licence, and indicate if changes were made. The images or other third party material in this article are included in the article's Creative Commons licence, unless indicated otherwise in a credit line to the material. If material is not included in the article's Creative Commons licence and your intended use is not permitted by statutory regulation or exceeds the permitted use, you will need to obtain permission directly from the copyright holder. To view a copy of this licence, visit http://creativecommons.org/licenses/by/4.0/.

\section{References}

Aittomäki, A., Lahelma, E., Roos, E., Leino-Arjas, P., \& Martikainen, P. (2005). Gender differences in the association of age with physical workload and functioning. Occupational and Environmental Medicine, 62(2), 95-100. https://doi.org/10.1136/oem.2004.014035

Andlauer, P., Reinberg, A., Fourré, L., Battle, W., \& Duverneuil, G. (1979). Amplitude of the oral temperature circadian rhythm and the tolerance to shift-work. Journal of Physiology (paris), 75(5), 507-512. 
Ardito, C., \& d'Errico, A. (2018). The dark side of work life extension: Health, welfare and equity concerns. Sociologia Del Lavoro, 150, 101-119. https://doi.org/10.3280/SL2018-150006

Ardito, C., Leombruni, R., Blane, D., \& d'Errico, A. (2020). To work or not to work? The effect of higher pension age on cardiovascular health. Industrial Relations, 59(3), 399-434. https://doi.org/10.1111/ irel.12257

Arpaia, A., \& Curci, N. EU labour market behaviour during the Great Recession. European Commission Directorate-General for Economic and Financial Affairs Publications, Economic Papers 405, 2010. https://doi.org/10.2765/39957

Barros, A. J., \& Hirakata, V. N. (2003). Alternatives for logistic regression in cross-sectional studies: An empirical comparison of models that directly estimate the prevalence ratio. BMC Medical Research Methodology, 3, 21. https://doi.org/10.1186/1471-2288-3-21

Belloni, M., Meschi, E., \& Pasini, G. (2016). The effect on mental health of retiring during the economic crisis. Health Economics, 25(Suppl 2), 126-140. https://doi.org/10.1002/hec.3377

Blake, H., \& Garrouste, C. (2019). Collateral effects of a pension reform in France. Annales D'économie Et De Statistique, 133, 57-86.

Bonde, J. P. (2008). Psychosocial factors at work and risk of depression: A systematic review of the epidemiological evidence. Occupational and Environmental Medicine, 65(7), 438-445. https://doi.org/10. 1136/oem.2007.038430

Boot, C. R., Deeg, D. J., Abma, T., Rijs, K. J., van der Pas, S., van Tilburg, T. G., \& van der Beek, A. J. (2014). Predictors of having paid work in older workers with and without chronic disease: A 3-year prospective cohort study. Journal of Occupational Rehabilitation, 24(3), 563-572. https://doi.org/10. 1007/s10926-013-9489-y

Burr, H., Pohrt, A., Rugulies, R., Holtermann, A., \& Hasselhorn, H. M. (2017). Does age modify the association between physical work demands and deterioration of self-rated general health? Scandinavian Journal of Work, Environment \&amp; Health, 43(3), 241-249. https://doi.org/10.5271/sjweh.3625

Camerino, D., Conway, P. M., Van der Heijden, B. I., et al. (2006). Low-perceived work ability, ageing and intention to leave nursing: A comparison among 10 European countries. Journal of Advanced Nursing, 56(5), 542-552. https://doi.org/10.1111/j.1365-2648.2006.04046.x

Capanni, C., Sartori, S., Carpentiero, G., \& Costa, G. (2005). Work ability index in a cohort of railway construction workers. In International congress series (Vol. 1280, pp. 253-257). Elsevier.

Carbonero, F., Ernst, E., \& Weber, E. (2020). Robots worldwide: The impact of automation on employment and trade. IAB Discussion Paper 7/2020, Leibniz Information Centre for Economics, Kiel, Hamburg.

Carrino, L., Glaser, K., \& Avendano, M. (2020). Later retirement, job strain, and health: Evidence from the new State Pension age in the United Kingdom. Health Economics, 29(8), 891-912. https://doi.org/10. 1002/hec.4025

Converso, D., Viotti, S., Sottimano, I., Cascio, V., \& Guidetti, G. (2015). Capacità lavorativa, salute psicofisica, burnout ed età, tra insegnanti d'infanzia ed educatori di asilo nido: uno studio trasversale [Work ability, psycho-physical health, burnout, and age among nursery school and kindergarten teachers: a cross-sectional study]. La Medicina Del Lavoro, 106(2), 91-108.

Costa, G., \& Sartori, S. (2007). Ageing, working hours and work ability. Ergonomics, 50(11), 1914-1930. https://doi.org/10.1080/00140130701676054

d'Errico, A. (2017). Aging of the workforce, retirement and health. In Aging and work e-book. CIIP. Retrieved from https://www.ciip-consulta.it/index.php?option=com_phocadownload\&view=file\&id= 12:aging-ebook-en\&Itemid $=609$.

da Costa, B. R., \& Vieira, E. R. (2010). Risk factors for work-related musculoskeletal disorders: A systematic review of recent longitudinal studies. American Journal of Industrial Medicine, 53(3), 285-323. https://doi.org/10.1002/ajim.20750

D'Amuri, F. (2011). The Impact of the Great Recession on the Italian Labour Market. In H. Immervoll, A. Peichl, \& K. Tatsiramos (Eds.), Who loses in the downturn? Economic crisis, employment and income distribution. Research in labor economics (Vol. 32, pp. 155-180). Emerald Group Publishing Limited. https://doi.org/10.1108/S0147-9121(2011)0000032008

Dauth, W., Findeisen, S., Suedekum, J., \& Woessner, N. (2018). Adjusting to robots: Worker-level evidence. Opportunity and Inclusive Growth Institute Working Papers, 13.

De Breij, S., Mäcken, J., Qvist, J. Y., et al. (2020). Educational differences in the influence of health on early work exit among older workers. Occupational and Environmental Medicine, 77(8), 568-575. https:// doi.org/10.1136/oemed-2019-106253

de Girolamo, G., Polidori, G., Morosini, P., Scarpino, V., Reda, V., Serra, G., Mazzi, F., Alonso, J., Vilagut, G., Visonà, G., Falsirollo, F., Rossi, A., \& Warner, R. (2006). Prevalence of common mental disorders in Italy: Results from the European Study of the Epidemiology of Mental Disorders 
(ESEMeD). Social Psychiatry and Psychiatric Epidemiology, 41(11), 853-861. https://doi.org/10. 1007/s00127-006-0097-4

de Zwart, B. C., Frings-Dresen, M. H., \& van Dijk, F. J. (1995). Physical workload and the aging worker: A review of the literature. International Archives of Occupational and Environmental Health, 68(1), 1-12. https://doi.org/10.1007/BF01831627

d'Errico, A., Burr, H., Pattloch, D., Kersten, N., \& Rose, U. (2020). Working conditions as risk factors for early exit from work-in a cohort of 2351 employees in Germany. International Archives of Occupational and Environmental Health. https://doi.org/10.1007/s00420-020-01566-x

Dorner, T. E., \& Mittendorfer-Rutz, E. (2017). Socioeconomic inequalities in treatment of individuals with common mental disorders regarding subsequent development of mental illness. Social Psychiatry and Psychiatric Epidemiology, 52(8), 1015-1022. https://doi.org/10.1007/s00127-017-1389-6

Dottori, D. (2021). Robots and employment: Evidence from Italy. Economia Politica 1-57.

Eibich, P. (2015). Understanding the effect of retirement on health: Mechanisms and heterogeneity. Journal of Health Economics, 43, 1-12. https://doi.org/10.1016/j.jhealeco.2015.05.001

Elsby, M. W., Hobijn, B., \& Sahin, A. (2010). The labor market in the great recession. NBER Working Paper No. 15979.

Eurofound (2017a). Working conditions of workers of different ages: European Working Conditions Survey 2015. Publications Office of the European Union.

Eurofound (2017b). Sixth European working conditions survey-Overview report (2017 update). Publications Office of the European Union.

Eurofound (2020). Labour market change: Trends and policy approaches towards flexibilisation. Challenges and prospects in the EU series, Publications Office of the European Union.

Eurostat (2019). Aging Europe. Looking at the lives of older people in the EU. Publications Office of the European Union.

Fabiani, M., Riccardo, F., Di Napoli, A., Gargiulo, L., Declich, S., \& Petrelli, A. (2016). Differences in influenza vaccination coverage between adult immigrants and Italian citizens at risk for influenzarelated complications: A cross-sectional study. PLOS ONE, 11(11), e0166517. https://doi.org/10. 1371/journal.pone.0166517

Fernandez-Lopez, J. C., Laffon, A., Blanco, F. J., Carmona, L., EPISER Study Group. (2008). Prevalence, risk factors, and impact of knee pain suggesting osteoarthritis in Spain. Clinical and Experimental Rheumatology, 26(2), 324-332.

Friis, K., Ekholm, O., Hundrup, Y. A., Obel, E. B., \& Gronbiek, M. (2007). Infuence of health, lifestyle, working conditions, and sociodemography on early retirement among nurses: The Danish nurse cohort study. Scandinavian Journal of Public Health, 35(1), 23-30. https://doi.org/10.1080/14034 940600777278

Gagliardi, F., Verma, V., \& Ciampalini, G. (2009). Methodology of European labour force surveys: (2) sample design and implementation. Department of Quantitative Methods, University of Siena, Working Paper no. 79.

Gourmelen, J., Chastang, J. F., Ozguler, A., Lanoë, J. L., Ravaud, J. F., \& Leclerc, A. (2007). Frequency of low back pain among men and women aged 30 to 64 years in France. Results of two national surveys. Annales De Readaptation Et De Medecine Physique, 50(8), 640-639. https://doi.org/10. 1016/j.annrmp.2007.05.009

Gouveia, N., Rodrigues, A., Eusébio, M., et al. (2016). Prevalence and social burden of active chronic low back pain in the adult Portuguese population: Results from a national survey. Rheumatology International, 36(2), 183-197. https://doi.org/10.1007/s00296-015-3398-7

Gummesson, C., Atroshi, I., Ekdahl, C., Johnsson, R., \& Ornstein, E. (2003). Chronic upper extremity pain and co-occurring symptoms in a general population. Arthritis and Rheumatism, 49(5), 697702. https://doi.org/10.1002/art.11386

Hoffmann, R., Kröger, H., \& Geyer, S. (2019). Social causation versus health selection in the life course: Does their relative importance differ by dimension of SES? Social Indicators Research, 141(3), 1341-1367. https://doi.org/10.1007/s11205-018-1871-x

Ilmarinen, J., Tuomi, K., \& Klockars, M. (1997). Changes in the work ability of active employees over an 11-year period. Scandinavian Journal of Work, Environment \&amp; Health, 23(Suppl 1), 49-57.

ISTAT (2008). Condizioni di salute e ricorso ai servizi sanitari. Nota metodologica. Available from: https:// www.istat.it/it/archivio/10836. Accessed 19 Oct 2021

Jedryka-Góral, A., Bugajska, J., Łastowiecka, E., et al. (2006). Work ability in ageing workers suffering from chronic diseases. International Journal of Occupational Safety and Ergonomics, 12(1), 17-30. https://doi.org/10.1080/10803548.2006.11076665 
Karpansalo, M., Manninen, P., Kauhanen, J., Lakka, T. A., \& Salonen, J. T. (2004). Perceived health as a predictor of early retirement. Scandinavian Journal of Work, Environment \&amp; Health, 30(4), 287-292. https://doi.org/10.5271/sjweh.796

Kiely, K. M., \& Butterworth, P. (2015). Validation of four measures of mental health against depression and generalized anxiety in a community based sample. Psychiatry Research, 225(3), 291-298. https://doi.org/10.1016/j.psychres.2014.12.023

Klenert, D., Fernandez-Macias, E., \& Antón Pérez, J. I. (2020). Do robots really destroy jobs? Evidence from Europe. JRC Working Papers Series on Labour, Education and Technology.

Koolhaas, W., van der Klink, J. J., de Boer, M. R., Groothoff, J. W., \& Brouwer, S. (2014). Chronic health conditions and work ability in the ageing workforce: The impact of work conditions, psychosocial factors and perceived health. International Archives of Occupational and Environmental Health, 87(4), 433-443. https://doi.org/10.1007/s00420-013-0882-9

Koolhaas, W., van der Klink, J. J., Groothoff, J. W., \& Brouwer, S. (2012). Towards a sustainable healthy working life: Associations between chronological age, functional age and work outcomes. European Journal of Public Health, 22(3), 424-429. https://doi.org/10.1093/eurpub/ckr035

Kröger, H. (2016). The contribution of health selection to occupational status inequality in Germanydifferences by gender and between the public and private sectors. Public Health, 133, 67-74. https://doi.org/10.1016/j.puhe.2015.10.022

Lallukka, T., Hiilamo, A., Pietiläinen, O., Mänty, M., Kouvonen, A., \& Rahkonen, O. (2020). Who maintains good health functioning? The contribution of social, work-related and behavioural factors to mental and physical health functioning trajectories in ageing employees. Occupational and Environmental Medicine, 77(7), 478-487. https://doi.org/10.1136/oemed-2019-106324

Leijten, F. R., de Wind, A., van den Heuvel, S. G., et al. (2015). The influence of chronic health problems and work-related factors on loss of paid employment among older workers. Journal of Epidemiology and Community Health, 69(11), 1058-1065. https://doi.org/10.1136/jech-2015-205719

Marinacci, C., d'Errico, A., Cardano, M., Perini, F., \& Costa, G. (2005). Differenze per professione nelle condizioni di lavoro nocive [Occupational differences in exposure to hazardous work conditions]. Medicina Del Lavoro, 96(Suppl), s127-s140.

Mezuk, B., Bohnert, A. S., Ratliff, S., \& Zivin, K. (2011). Job strain, depressive symptoms, and drinking behavior among older adults: Results from the health and retirement study. Journals of Gerontology. Series b, Psychological Sciences and Social Sciences, 66(4), 426-434. https://doi.org/10.1093/ geronb/gbr021

Miranda, H., Kaila-Kangas, L., Heliövaara, M., et al. (2010). Musculoskeletal pain at multiple sites and its effects on work ability in a general working population. Occupational and Environmental Medicine, 67(7), 449-455. https://doi.org/10.1136/oem.2009.048249

Niedhammer, I., Chastang, J. F., \& David, S. (2008). Importance of psychosocial work factors on general health outcomes in the national French SUMER survey. Occupational Medicine (london), 58(1), 15-24. https://doi.org/10.1093/occmed/kqm115

Nyberg, A., Peristera, P., Magnusson Hanson, L. L., \& Westerlund, H. (2019). Socio-economic predictors of depressive symptoms around old age retirement in Swedish women and men. Aging \&amp; Mental Health, 23(5), 558-565. https://doi.org/10.1080/13607863.2018.1430741

Odone, A., Landriscina, T., Amerio, A., \& Costa, G. (2018). The impact of the current economic crisis on mental health in Italy: Evidence from two representative national surveys. European Journal of Public Health, 28(3), 490-495. https://doi.org/10.1093/eurpub/ckx220

Okunribido, O. O., Wynn, T., \& Lewis, D. (2011). Are older workers at greater risk of musculoskeletal disorders in the workplace than young workers? A literature review. Occupational Ergonomics, 10(12), 53-68. https://doi.org/10.3233/oer-2010-0192

Pejtersen, J. H., Burr, H., Hannerz, H., Fishta, A., \& Hurwitz, E. N. (2015). Update on work-related psychosocial factors and the development of ischemic heart disease: A systematic review. Cardiology in Review, 23(2), 94-98. https://doi.org/10.1097/CRD.0000000000000033

Plouvier, S., Gourmelen, J., Chastang, J. F., Lanoë, J. L., \& Leclerc, A. (2011). Low back pain around retirement age and physical occupational exposure during working life. BMC Public Health, 11, 268. https://doi.org/10.1186/1471-2458-11-268

Qiao, Y. M., Lu, Y. K., Yan, Z., Yao, W., Pei, J. J., \& Wang, H. X. (2019). Reciprocal associations between job strain and depression: A 2-year follow-up study from the Survey of Health, Ageing and Retirement in Europe. Brain and Behavior: A Cognitive Neuroscience Perspective, 9(9), e01381. https://doi.org/10.1002/brb3.1381

Reyneri, E. (2018). Le due grandi crisi del mercato del lavoro italiano: gli anni Trenta del XX secolo a confronto con gli anni Dieci del XXI secolo. In ISTAT, La Società Italiana e le grandi crisi economiche 1929-2016. Annali di Statistica, Anno 147 - Serie XIII (Vol. 2). 
Robroek, S. J., Schuring, M., Croezen, S., Stattin, M., \& Burdorf, A. (2013). Poor health, unhealthy behaviors, and unfavorable work characteristics influence pathways of exit from paid employment among older workers in Europe: A four year follow-up study. Scandinavian Journal of Work, Environment \&amp; Health, 39(2), 125-133. https://doi.org/10.5271/sjweh.3319

Saastamoinen, P., Leino-Arjas, P., Laaksonen, M., \& Lahelma, E. (2005). Socio-economic differences in the prevalence of acute, chronic and disabling chronic pain among ageing employees. Pain, 114(3), 364-371. https://doi.org/10.1016/j.pain.2004.12.033

Saksvik, I. B., Bjorvatn, B., Hetland, H., Sandal, G. M., \& Pallesen, S. (2011). Individual differences in tolerance to shift work: A systematic review. Sleep Medicine Reviews, 15(4), 221-235. https://doi. org/10.1016/j.smrv.2010.07.002

Scharn, M., Oude Hengel, K., Boot, C. R. L., Burdorf, A., Schuring, M., van der Beek, A. J., \& Robroek, S. J. W. (2019). Influence of chronic diseases on societal participation in paid work, volunteering and informal caregiving in Europe: A 12-year follow-up study. Journal of Epidemiology and Community Health, 73(2), 136-141. https://doi.org/10.1136/jech-2018-211107

Schuring, M., Burdorf, L., Kunst, A., \& Mackenbach, J. (2007). The effects of ill health on entering and maintaining paid employment: Evidence in European countries. Journal of Epidemiology and Community Health, 61(7), 597-604. https://doi.org/10.1136/jech.2006.047456

Schuring, M., Robroek, S. J., Otten, F. W., Arts, C. H., \& Burdorf, A. (2013). The effect of ill health and socioeconomic status on labor force exit and re-employment: A prospective study with ten years follow-up in the Netherlands. Scandinavian Journal of Work, Environment \&amp; Health, 39(2), 134143. https://doi.org/10.5271/sjweh.3321

Siegrist, J., Lunau, T., Wahrendorf, M., \& Dragano, N. (2012). Depressive symptoms and psychosocial stress at work among older employees in three continents. Global Health, 8, 27. https://doi.org/10. $1186 / 1744-8603-8-27$

Sim, J., Lacey, R. J., \& Lewis, M. (2006). The impact of workplace risk factors on the occurrence of neck and upper limb pain: A general population study. BMC Public Health, 6, 234. https://doi.org/10.1186/ 1471-2458-6-234

Sundstrup, E., Hansen, Å. M., Mortensen, E. L., Poulsen, O. M., Clausen, T., Rugulies, R., Møller, A., \& Andersen, L. L. (2018). Retrospectively assessed physical work environment during working life and risk of sickness absence and labour market exit among older workers. Occupational and Environmental Medicine, 75(2), 114-123. https://doi.org/10.1136/oemed-2016-104279

Theorell, T., Hammarström, A., Aronsson, G., et al. (2015). A systematic review including meta-analysis of work environment and depressive symptoms. BMC Public Health, 15, 738. https://doi.org/10.1186/ s12889-015-1954-4

Theorell, T., Jood, K., Järvholm, L. S., et al. (2016). A systematic review of studies in the contributions of the work environment to ischaemic heart disease development. European Journal of Public Health, 26(3), 470-477. https://doi.org/10.1093/eurpub/ckw025

Tobia, L., Giammaria, A., Pizzuti, S., Gioia, F., Lupi, A., Spera, G., \& Paoletti, A. (2005). Elderly workers in chemical, energetic, sanitary and public fields: Evaluation of work ability. In International congress series (Vol. 1280, pp. 322-327). Elsevier.

van den Berg, T., Schuring, M., Avendano, M., Mackenbach, J., \& Burdorf, A. (2010). The impact of ill health on exit from paid employment in Europe among older workers. Occupational and Environmental Medicine, 67(12), 845-852. https://doi.org/10.1136/oem.2009.051730

Venema, A., Heuvel, S., \& Geuskens, G. (2009). Health and safety at work: Results of the Labour Force Survey 2007 ad hoc module on accidents at work and work-related health problems. TNO.

Wanberg, C. R., Kanfer, R., Hamann, D. J., \& Zhang, Z. (2016). Age and reemployment success after job loss: An integrative model and meta-analysis. Psychological Bulletin, 142(4), 400-426. https://doi.org/ $10.1037 /$ bul0000019

Publisher's Note Springer Nature remains neutral with regard to jurisdictional claims in published maps and institutional affiliations. 


\section{Authors and Affiliations}

Angelo d'Errico ${ }^{1} \cdot$ Chiara Ardito $^{1,2}$ (D) Roberto Leombruni ${ }^{2} \cdot$ Fulvio Ricceri $^{1,3}$. Giuseppe Costa $^{1,3} \cdot$ Carlotta Sacerdote ${ }^{4,5} \cdot$ Anna Odone $^{6} \cdot$ the "Italian Working Group on Retirement and Health"

1 Present Address: Department of Epidemiology, Piedmont Region, ASL TO3 Grugliasco, Turin, Italy

2 Department of Economics and Statistics "Cognetti De Martiis”, University of Turin, Lungo Dora Siena 100A, 10153 Turin, Italy

3 Department of Clinical and Biological Sciences, University of Turin, Turin, Italy

4 Unit of Cancer Epidemiology, University of Turin, Turin, Italy

5 Centre for Cancer Epidemiology and Prevention (CPO Piemonte), Turin, Italy

6 Department of Public Health, Experimental and Forensic Medicine, University of Pavia, Pavia, Italy

7 Department of Neuroscience, Rehabilitation, Ophthalmology, Genetics, Maternal and Child Health, Section of Psychiatry, University of Genoa, Genoa, Italy

8 IRCCS Ospedale Policlinico San Martino, Genoa, Italy

9 Laboratory of Medical Statistics, Biometry and Epidemiology “G.A. Maccacaro", Department of Clinical Sciences and Community Health, University of Milan, Milano, Italy

10 School of Medicine, University Vita-Salute San Raffaele, Milan, Italy

11 IRCCS Fondazione San Matteo, Pavia, Italy

12 Department of Social and Political Sciences, Bocconi University, Milan, Italy 